\title{
Understory Bamboo Discrimination Using a Winter Image
}

\author{
Tiejun Wang, Andrew K. Skidmore, Albertus G. Toxopeus, and Xuehua Liu
}

\begin{abstract}
In this study, a new approach is presented that combines forest phenology and Landsat vegetation indices to estimate evergreen understory bamboo coverage in a mixed temperate forest. It was found that vegetation indices, especially the normalized difference vegetation index (NDVI) derived from leaf-off (winter) images were significantly correlated with percent understory bamboo cover for both deciduous and mixed coniferous/deciduous forests. Winter NDVI was used to map bamboo coverage using a binary decision tree classifier. A high mapping accuracy for understory bamboo presence/absence was achieved with an overall accuracy of 89 percent $(\kappa=0.59)$. In addition, for the first time, we successfully classified three density classes of bamboo with an overall accuracy of 68 percent $(\kappa=0.48)$. These results were compared to three traditional multispectral bandsbased methods (Mahalanobis distance, maximum likelihood, and artificial neural networks). The highest mapping accuracy was again obtained from winter images. However, the kappa z-test showed that there was no statistical difference in accuracy between the methods. The results suggest that winter is the optimal season for quantifying the coverage of evergreen understory bamboos in a mixed forest area, regardless of the classification methods use.
\end{abstract}

\section{Introduction}

Understory plants are important elements of forest structure and composition, providing habitat and forage for wildlife, and contributing to flora diversity (McKenzie and Halpern, 1999; Rettie et al., 1997). Bamboos are typical understory tree-grasses in Japanese, Chilean, and Chinese temperate and subalpine forests where they achieve a high degree of dominance (Franklin et al., 1979; Taylor and Qin, 1988; Veblen, 1982). Many mammals and birds rely on this special niche as sites for foraging and nesting, in which the most famous are giant panda (Ailuropoda melanoleuca), red panda (Ailurus fulgens), and golden pheasant (Chrysolophus pictu) (Gong et al., 2006; Reid et al., 1991; Reid et al., 2004; Schaller et al., 1985). Knowledge of understory bamboo presence/absence and its abundance would enable wildlife managers to identify areas of suitable habitat for dependent animals and birds

Tiejun Wang, Andrew K. Skidmore, and Albertus G. Toxopeus are with the Department of Natural Resources, International Institute for Geo-Information Science and Earth Observation (ITC), P.O. Box 6, 7500 AA Enschede, The Netherlands (tiejun@itc.nl).

Xuehua Liu is with the Department of Environmental Science and Engineering, Tsinghua University, Beijing 100084, China.
(Borkowski and Furubayashi, 1998; Diaz et al., 2005; Liu et al., 2005; Reid et al., 2004; Warner, 2002). However, our understanding of understory bamboo spatial distribution at local and national levels is limited, as previous studies focused on ground surveys executed over small and intensively study sites. In addition, the complexity of bamboo distribution, influenced by human activities (clear cutting and fire), as well as periodical mass flowering and die-off (Reid et al., 1989), makes the up-scaling to large areas through conventional point-based environmental modeling extremely difficult. A few studies have been conducted at large landscape level. For example, the panda habitat assessment in the Wolong Nature Reserve of Sichuan (Liu et al., 2001) and the Qinling Mountains of Shaanxi (Loucks et al., 2003) in China assumed that the distribution of understory bamboo has a constant spatial cover. In these studies the authors noted that the unsuitable habitat would be underestimated, because critical information affecting panda habitat, such as bamboo distribution, was not available for the entire region.

Remote sensing may be suitable for mapping forest understory across large areas. For example, Morain (1986) conducted a primary investigation on understory bamboo assessment in a Chinese panda reserve using $35 \mathrm{~mm}$ color infrared air photographs (scale 1:12 000) acquired in April (leaf-off season). He reported that three types of understory bamboo status (mixed with deciduous trees, mixed with coniferous trees, and mainly deciduous vegetation without bamboo) may be visually distinguished. By utilizing summer TM image and an unsupervised classification approach, Stenback and Congalton (1990) detected presence and absence of vegetated understory for different canopy closures in the Sierran mixed conifer zone with an overall accuracy range from 55 to 69 percent and kappa coefficient $(\kappa)$ range from 0.08 to 0.38 . Linderman et al. (2004) mapped the presence and absence of understory bamboos in a Chinese mixed temperate forest using leaf-on Landsat image and an artificial neural network algorithm, achieving an overall mapping accuracy of 80 percent ( $\kappa$ value not stated). More recently, Joshi et al. (2006) developed a remotely sensed data and understory lightclimate-based model to predict the presence and absence of an understory invasive species (Chromolaena odorata) in Nepal, and obtained an overall mapping accuracy of 74 percent $(\kappa=0.56)$. These studies demonstrate that remote sensing methods can quantify understory species. However, there are conflictive definitions of understory species for presence and absence that make comparisons difficult, and may have biased

Photogrammetric Engineering \& Remote Sensing Vol. 75, No. 1, January 2009, pp. 37-47.

0099-1112/09/7501-0037/\$3.00/0 (C) 2009 American Society for Photogrammetry and Remote Sensing 
the quality of results for particular studies. For example, the research of Stenback and Congalton (1990) defined "presence" as greater than 50 percent vegetated cover, Linderman et al. (2004) defined "presence" as greater than 10 percent, and Joshi et al. (2006) defined an absolute presence or absence of understory invasive species. In this study, we defined a priori three cover classes densities, i.e., the bamboo absence ( $<1$ percent), low bamboo cover ( 1 to 50 percent), and high bamboo cover ( $>50$ percent). Furthermore, the phenological difference between overstory and understory and its impact on understory detection has not been examined in previous studies. Our research complements and extends these analyses by comparing the difference in understory mapping accuracy as influenced by image acquisition time, i.e., phenology.

Vegetation indices (VIs) are a popular tool to relate remotely sensed data to many biophysical parameters of vegetation such as leaf area index (LAI), fractional absorption of photosynthetically active radiation (FPAR), percent green cover (Turner et al., 1999; Huete et al., 2002; Myneni et al. 2002). The cover class densities of green vegetation have been linked to vegetation indices (Dymond et al., 1992; Purevdorj et al., 1998; Wittich and Hansing, 1995). Vegetation indices are physically based on the differential scattering and absorption of a green leaf, and specifically the absorption of incident red light by plant chlorophyll and scattering of incident near-infrared (NIR) radiation by plant leaves (Myneni, 1995). Most of the VIs are so-called "broadband" vegetation indices because they capture this contrast through algebraic combinations of these two spectral bands. These various combinations have been claimed to minimize and normalize the effect of external influences, such as solar irradiance changes due to the atmospheric effect (Kaufman and Tanré, 1992), or variations in soil background (Huete, 1988), illumination and topographic (Colby, 1991; Huete, 1988; Kaufman and Tanré, 1992). Vegetation indices are simple and easy to use and allow operational monitoring of the Earth's vegetative cover at local, regional, and global scale biomes (Townshend et al., 1991; Tucker et al., 1985).

As dense overstory forest and co-occurrence of other understories significantly contribute to remote sensingderived vegetation indices during the growing season, the first hypothesis for this study is that vegetation indices derived from winter (leaf-off) imagery can be used to detect the presence and absence of bamboo as well as to quantify the cover degree of evergreen understory bamboo species.
Seasonal change is a common natural phenomenon in forested landscapes occurring on an annual basis. By considering the seasonal variation of vegetation (phenology), more accurate vegetation maps have been obtained. For example, Goodenough et al. (2001) compared classification accuracies achieved for forest classes with single leaf-on date and paired image sets of leaf-on and leaf-off condition. They concluded that the inclusion of the leaf-off data sharply delineates the signatures of the deciduous components in the imagery, resulting in increased overall classification accuracy. Townsend and Walsh (2001) classified forest wetland communities in the southeast U.S. using a multitemporal approach with leaf-off and leaf-on images to successfully identify mixes of deciduous and evergreen species. This approach was also used by Flores et al. (2003) to effectively estimate LAI of evergreen overstory and the deciduous understory component. However, such approaches have not been previously used to map and quantify evergreen understory species. A second hypothesis for this study is that compared to the leaf-on, partial leaf-on, and partial leaf-off images, the leaf-off image consistently yields the most accurate results for mapping evergreen understory bamboo, regardless of the classification method used.

Based on the above hypotheses, the objectives of this study were to: (a) assess whether vegetation indices derived from winter (leaf-off) imagery may successfully map understory bamboo cover in a mixed temperate forest and, if so, then (b) to compare the mapping accuracies of the vegetation index thresholds-based decision tree approach with the traditional multispectral bands-based classifiers.

\section{Study Area}

The study area, Foping Biosphere Reserve, is located on the south slope of the Qinling Mountains in China $\left(33^{\circ} 32^{\prime}\right.$ to $33^{\circ} 45^{\prime} \mathrm{N}, 107^{\circ} 40^{\prime}$ to $107^{\circ} 55^{\prime} \mathrm{E}$ ). The reserve covers an area of $294 \mathrm{~km}^{2}$ and with elevation ranges from about 1,000 to $2,900 \mathrm{~m}$ (Figure 1). It is one of the few reserves for intact ecosystems, as well as the most populated giant panda habitat in China. The current research focuses on the lower elevation areas below $2,000 \mathrm{~m}$. A digital elevation model (DEM) of the study area was used to mask all the images used in the study.

Forest is the major land-cover and accounts for 98 percent of total land area in this reserve. The vegetation (below $2,000 \mathrm{~m}$ ) is principally dominated by deciduous broadleaf forest, with some interspersed areas of mixed coniferous and

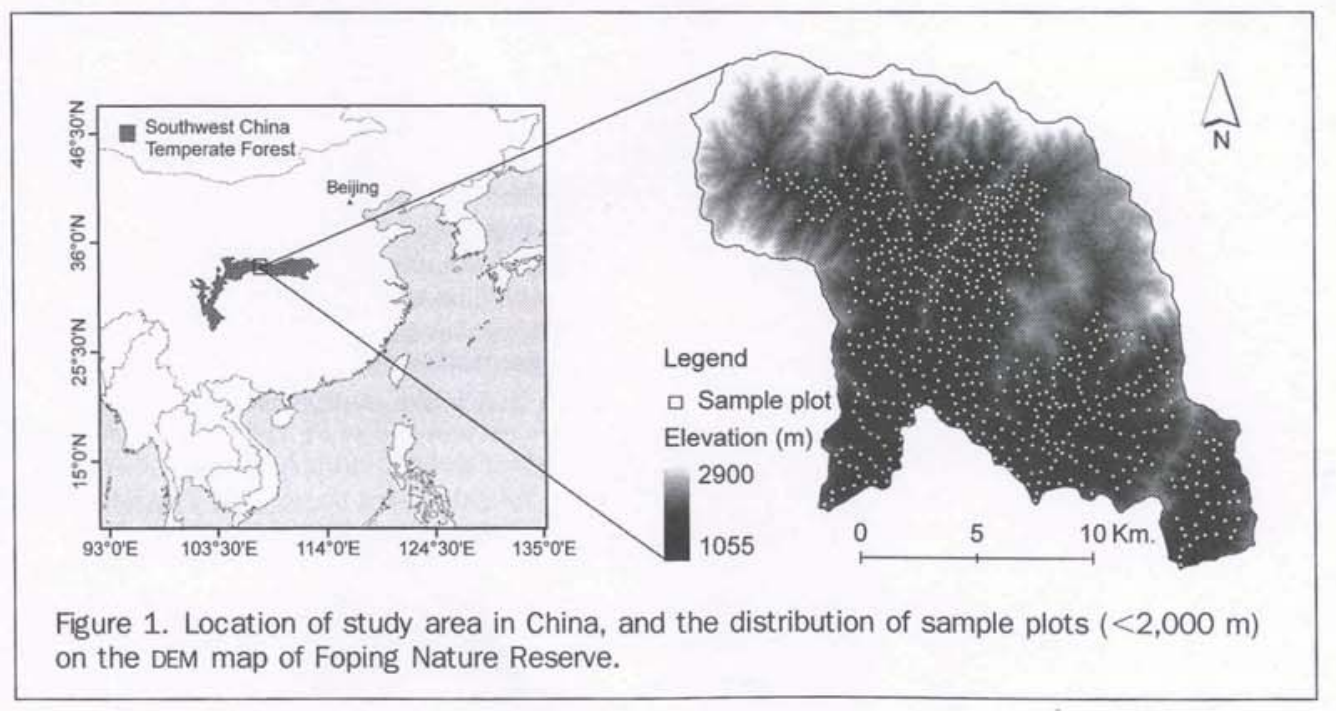


deciduous broadleaf forests (Yue et al., 1999). The dominant deciduous broadleaf tree species are oaks (Quercus spp.), poplars (Populus spp.), and birches (Betula spp.) while the most common evergreen needleleaf tree species are pines (Pinus spp.) and fir (Tsuga chinensis). Canopy trees in this area leaf-out in mid-April to late-May, while leaf-fall is complete by mid-October to early-November. The midstory and understory layers (shrubs and saplings) are dominated by Bashania fargesii, Abelia engleriana, Lespedeza bicolor, and Listea pungens. The dominant forest floor layer (herbs) is Carex lanceolata. However, there are no preponderant shrubs and herbs once the bamboo dominates the forest understory (Ren et al., 1998). The co-occurrence of other understories is depended on the cover of bamboo, Bashania fargesii.

The cool, wet climate and fertile soils in Foping reserve provides ideal conditions for bamboo to thrive in the understory of multiple vegetation types. Bashania fargesii, a typical evergreen understory bamboo species dominates the study area. It grows in an elevation belt between 1,000 to $2,000 \mathrm{~m}$, where the pandas usually spend three quarters of the year (Liu et al., 2002). B. fargesii establishs new shoots in May. Culms vary in basal diameter from 1 to $2 \mathrm{~cm}$, and grow to an average height of $2.5 \mathrm{~m}$. The undulating topography provides for a broad range of microclimates, which influences different growth phases of bamboo over relatively short distances. In forested areas, B. fargesii is distributed in patches, ranging in size from single plants to hundreds of meters across.

\section{Methods}

\section{Ground Survey Data}

The data used in this study were collected during field campaigns conducted as part of missions for China's Third National Giant Panda Survey between 1999 and 2000 in Foping Nature Reserve. As noted in the Introduction, evergreen bamboo is a resilient perennial which changes in area or cover very little over a period of a few years (Taylor et al. 1987). In contrast, the overstory in this area is deciduous and exhibits dramatic seasonal variation due to leaf senescence and flush (Pan et al., 1988), with these seasonal leaf-on and leaf-off phenomena being obvious on summer and winter images, respectively. In other words, the seasonal state of a pixel may be inferred from the change in the overstory forest cover. As a consequence, there was no attempt to sample each individual (seasonal) image in the field, as such an effort would be redundant in terms of ground checking land-cover. In general, the study area is inaccessible, especially due to snow in the winter months. A total of 646 sample plots (65 plots in 1999 and 581 plots in 2000) were carefully selected from the survey database based on three criteria: (a) the position of plots was below $2,000 \mathrm{~m}$, (b) the horizontal distance between adjacent plots was at least $300 \mathrm{~m}$, and (c) a strong satellite signal was received by a Garmin 12XL GPS unit, which means at least four satellites were located well above the horizon. Using the method of Ardö and Pilesjö (1992), we tested that the GPS precision was less than 10 meters for 95 percent of observations. A stratified random sampling based on the terrain position (i.e., valley, mid-slope, and ridge) was adopted in both surveys to ensure the representative habitat types can be collected over the mountains terrain. The sample plots were $20 \mathrm{~m} \times 20 \mathrm{~m}$, and were recorded where bamboo coverage was relatively homogeneous over a $60 \mathrm{~m} \times 60 \mathrm{~m}$ area. Within the plots, many biotic and abiotic variables were measured such as location, slope aspect, slope gradient, slope position, distance to water source, tree species, average tree height, percent bamboo cover, and panda signs. Furthermore, five subplots
( $2 \mathrm{~m} \times 2 \mathrm{~m}$ ) were also established within each $20 \mathrm{~m} \times$ $20 \mathrm{~m}$ plot to measure the bamboo characteristics in detail, such as total culm density and proportion of old shoots, average height and basal diameter. In this study, only three variables were used which are GPS position, tree species (presence/absence of conifer), and percent bamboo cover. The bamboo cover was visually estimated in the field and assigned to one of the following classes: $<1$ percent, 1 to 24 percent, 25 to 49 percent, 50 to 74 percent, and $>74$ percent following the methods described by (Kent and Coker, 1992; Taylor and Qin 1988; State Forestry Administration, 2006). Note that the visual estimation of understory bamboo coverage was based on two factors: the proportion of gap size between the bamboo patches and abundance of bamboo culms within the field plot. In the field, measurement crews used photographs of different canopy densities as templates to calibrate and standardize estimates of bamboo cover (between crews as well as over time). Typical photographs of bamboo density ranging from no bamboo $(<1$ percent) to very high cover ( $>74$ percent) are shown in Figure 2a through 2e.

\section{Landsat TM/ETM + Images and Preprocessing}

Four seasons of clear and systematically corrected (Level 2) Landsat images were purchased from the China Remote Sensing Satellite Ground Station (Table 1). Considering that the study area has been well-protected over the past 30 years and the bamboo density change is relatively slow underneath the mature forest (Tian and Liu, 1985), the dominant cover of understory bamboo associated with the different images remained similar. These images were projected to a UTM projection in WGS84 datum. Co-registration was conducted based on an independent orthorectified Landsat-7 ETM+ product (http://glcfapp.umiacs.umd.eud). This product was selected as the master image because (a) it is an orthorectified image and the relief displacement was corrected, and (b) it contained the highest positional accuracy with respect to the ground measurements after a slight geometric modification using an additional 20 local ground control points (GCPs) located uniformly across the image at clear features including river junctions, roads, and rock outcrops. The GCPs were collected using a Trimble Pro XRS differential GPS in 2005. A second order polynomial transformation model with bilinear interpolation was used for the geometric correction of the orthorectified image within the ERDAS Imagine ${ }^{\circledast}$ software package. The resulting images had a spatial resolution of $28.5 \mathrm{~m}$, and all images had a RMSE of less than 0.5 pixel $(<14 \mathrm{~m})$. Because this study involved analysis of biophysical parameters derived from multiseasonal images in a mountains terrain, it was necessary to perform atmospheric, topographic and radiometric correction to convert digital numbers to surface reflectance values. It is well known that winter images are difficult to process with respect to shading problems in areas of high terrain. We therefore made atmospheric and terrain corrections using ATCOR (Atmospheric and Topographic CORrection), an algorithm written by DLR (German Aerospace Agency) for mountainous terrain which is an add-on module to ERDAS Imagine ${ }^{\oplus}$ and uses look-up tables computed with the MODTRAN-4 radiative transfer code (Richter, 1996 and 1998) and applied Stefanov et al. (2001) and Greeberg et al (2005). The ATCOR algorithm was run using parameters found within the image metadata as well as partially provided and calculated by the package itself, such as the sensor pre-launch calibration file and sun position. Information about elevation, slope, aspect, skyview, and shadow derived from a DEM was employed to correct terrain effects. The DEM was obtained from a 1:50 000 scale contour map 


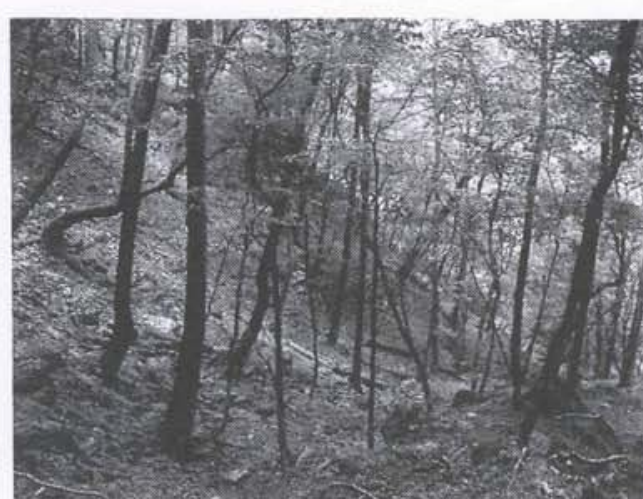

(a)

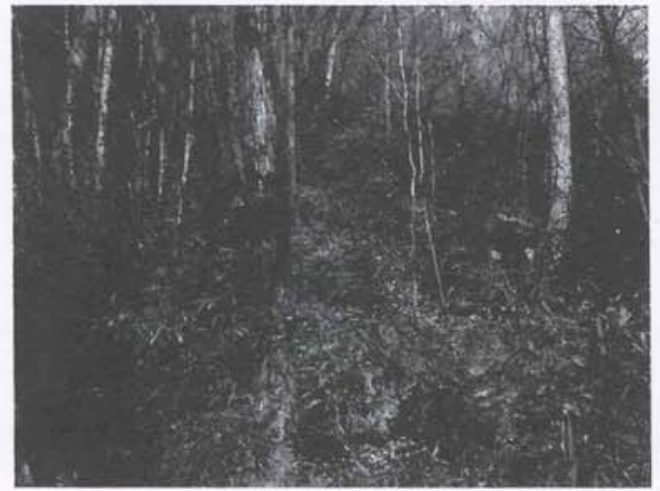

(c)

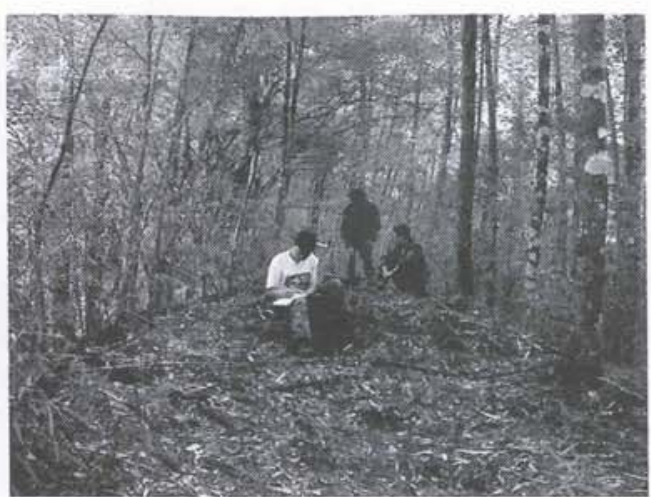

(b)

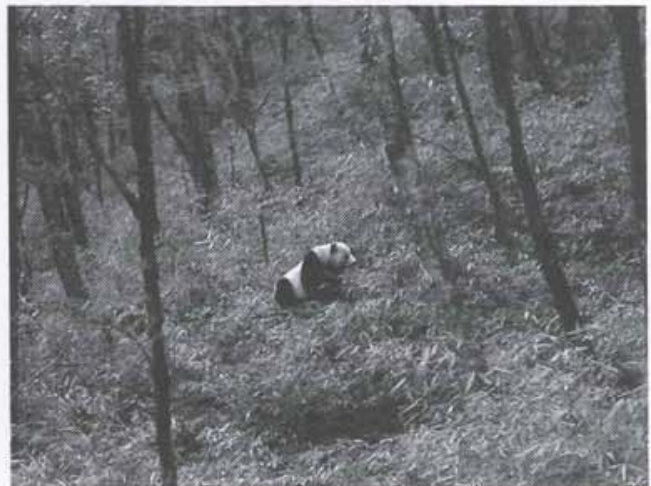

(d)

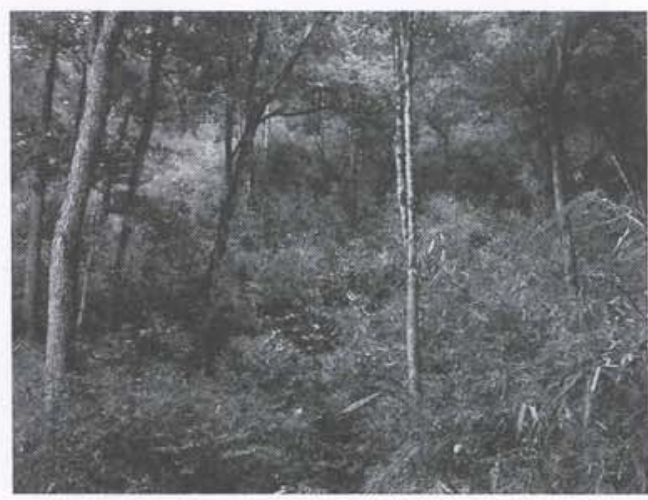

(e)

Figure 2. Examples of the bamboo ( $B$. fargesii) coverage: (a) No bamboo ( $<1$ percent), (b) Very low cover ( 1 to 24 percent), (c) Low cover ( 25 to 49 percent), (d) High cover (50 to 74 percent), and (e) Very high cover ( $>74$ percent) beneath overstory forest in the Foping Nature Reserve.

TABLE 1. ChARACTERISTICS OF LANDSAT TM/ETM + IMAGES USED IN THIS STUdY

\begin{tabular}{lcclll}
\hline Acquisition date & Landsat satellite & Path/Row & Season & Phenology & Note \\
\hline 22 May 2001 & 7 ETM & $128 / 37$ & Spring & Partly leaf-on & Master image \\
19 May 2000 & 7 ETM & $128 / 37$ & Spring & Partly leaf-on & Co-registration \\
30 July 2000 & 5 TM & $128 / 37$ & Summer & Leaf-on & Co-registration \\
19 October 1997 & 5 TM & $127 / 37$ & Autumn & Partly leaf-off & Co-registration \\
20 March 2001 & 5 TM & $127 / 37$ & Winter & Leaf-off & Co-registration \\
\hline
\end{tabular}


Table 2. Categories of Vegetation Indices Used in the Study

\begin{tabular}{|c|c|c|c|}
\hline VI & Formula & Reference & Note \\
\hline NDVl & $\frac{\rho_{\text {nir }}-\rho_{\text {red }}}{\rho_{\text {nir }}+\rho_{\text {red }}}$ & Rouse et al. (1973) & $\begin{array}{l}\text { Reduce terrain effect and sensitive to } \\
\text { green vegetation }\end{array}$ \\
\hline SAVI & $\frac{\rho_{\text {nir }}-\rho_{\text {red }}}{\rho_{\text {nir }}+\rho_{\text {red }}+L}(1+L)$ & Huete (1988) & $\begin{array}{l}\text { Reduce non-canopy background effect and } \\
\text { better in low biomass situation }\end{array}$ \\
\hline EVI & $G^{\star} \frac{\rho_{\text {nir }}-\rho_{\text {red }}}{\rho_{\text {nir }}+C_{1}{ }^{*} \rho_{\text {red }}-C_{2}{ }^{\star} \rho_{\text {blue }}+L}$ & Liu and Huete (1995) & $\begin{array}{l}\text { Reduce atmospheric influence and improved } \\
\text { performance in high biomass }\end{array}$ \\
\hline
\end{tabular}

with $20 \mathrm{~m}$ contours, developed by the State Bureau of Surveying and Mapping of China (1987). A mid-latitude, rural aerosol concentration model with $30 \mathrm{~km}$ estimated visibility (the estimation is based on actual observations from Hanzhong airport located $60 \mathrm{~km}$ from the study area) therefore was used as input to the radiative transfer code, respectively. Each image (spring, summer, autumn, winter) was individually processed. Thus, the output from ATCOR is a reflectance image corrected for radiometric and terrain effects.

\section{Calculating Vegetation Indices}

It is impractical to test all available vegetation indices. Therefore, three key indices were used (Table 2), selected because their design represents three important improvements in VI development to minimize the effect of topographic, soil background and atmospheric variations. The $\rho_{\text {blue }}, \rho_{\text {red }}, \rho_{\text {nir }}$ in NDVI, SAVI, and EVI are the surface reflectance factors for their respective TM and ETM+ bands; $L$ is a canopy background adjustment factor, which adopted in SAVI is a constant soil line of 0.5. $C_{1}$ and $C_{2}$ are the coefficients of the aerosol resistance term, which uses the blue band to correct for aerosol influences in the red band. The coefficients adopted in the EVI algorithm are, $L=1, C_{1}=6, C_{2}=7.5$, and $G$ (gain factor) $=2.5$.

\section{Determining Optimal Season and Vegetation Index}

The original 646 sample plots of five cover classes of bamboo estimated in the field were combined into three broad cover classes, which are bamboo absence ( $<1$ percent), low bamboo cover ( 1 to 50 percent), and high bamboo cover ( $>50$ percent). Additionally, the occurrence of evergreen conifers in our study site is a major problem because conifers mix with the evergreen understory bamboo in the leaf-off season. Therefore, the datasets were split into two groups according to the presence (317 samples) and absence (329 samples) of evergreen conifers in each plot. Training and testing samples were randomly selected ( 321 samples for training and 325 samples for testing). The three vegetation indices values were extracted for each training sample for images of the four seasons. Correlation analysis between the three vegetation indices and the three classes of bamboo coverage, for the four seasons, was performed using a multiple $R$-square tests (StatSoft, Inc., 2001). The results were used to identify which season image, and which vegetation index is most suitable for mapping evergreen understory bamboo coverage.

\section{Mapping the Presence/Absence of Conifer Overstory}

In order to achieve the highest mapping accuracy for classification of conifer overstory, three commonly used classification methods, Mahalanobis distance classifier (MDC), maximum likelihood classifier (MLC), and artificial neural networks (ANN) were tested on the four seasonal Landsat images. In this study, a three-layer, feed-forward, error-backpropagation artificial neural network implemented in Interactive Data Language (IDL) was used (Skidmore et al. 1997). Both MDC and MLC classifiers were implemented in ENVI version 4.2. The sample plots of the presence/absence of conifer were randomly divided into two equal groups, a training set (323 samples) and a test set ( 323 samples). Six Landsat TM/ETM + bands ( 1 through 5 , and 7) were included in the classification. The highest accuracy map for the presence/absence of conifer was then used as an input layer for the vegetation index thresholds-based decision tree approach.

\section{Linking Vegetation Index to Bamboo Presence and Coverage}

Once the optimal season image and vegetation index were determined, the midpoint between the mean vegetation indexes values derived from three classes of bamboo coverage were selected. A decision tree classifier (DTC) was employed to link bamboo presence and coverage to the vegetation indices. The DTC is a multistage classifier made up of a series of binary decisions that are used to determine the correct category for each pixel. The details of DTC is described in Hansen et al., (1996) and ENVI version 4.2 (Research Systems, Inc., 2005). In recent years, the DTC techniques have been successfully used for a wide range of classification problems and are becoming an important tool for the classification of remotely sensed data $(\mathrm{Pal}$ and Mather, 2003; Simard et al., 2000; Xu et al., 2005). These techniques have advantages for land-use and land-cover classification because of their flexibility, nonparametric nature, and ability to handle non-liner relations between features and classes. The decisions can be based on any available characteristic of the dataset, while the tree structure gives easily understandable and interpretable information regarding the predictive or generalization ability of the data. In this study, for example, the DTC is based on a set of vegetation index thresholds, a vegetation index map, a DEM used to mask the specific study areas below $2,000 \mathrm{~m}$, and a land-cover map of presence/absence of conifer overstory. Figure 3 presents the structure and parameters of decision tree which used to classify three classes of bamboo coverage.

\section{Mapping Bamboo Coverage Using Multispectral Bands-based Approach} The three classifiers (MDC, MLC, and ANN) applied to classify conifers were further used to map the understory bamboo presence/absence and coverage using four seasons of Landsat imagery. Only six TM/ETM + bands (excluding the thermal and panchromatic bands) were used by these classifiers. In order to compare the results, the same training and test datasets as used for the vegetation index-based decision tree approach were also applied to these three multispectral bands-based classifiers. The overall mapping accuracy and kappa coefficient (Cohen, 1960) were calculated, and a widely applied kappa z-test (Congalton et al., 


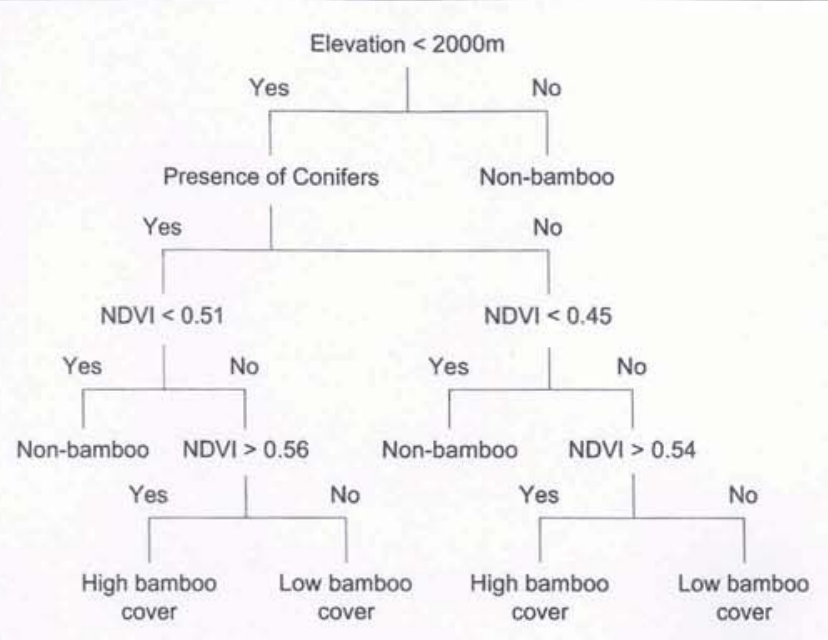

Figure 3. The structure of decision tree classifier and its parameters for three classes of bamboo coverage.
Table 4. Comparison of Overall. Mapping Accuracy and Kappa CoeffiCIENT FOR CLASSIFICATION OF CONIFER OVERSTORY FROM THREE DIFFERENT Classifiers (MDC, MLC, and ANN) In Four Seasons; Note that the OVA $=$ OVERALL ACCURACY

\begin{tabular}{|c|c|c|c|c|c|c|}
\hline \multirow[t]{2}{*}{ Seasons } & \multicolumn{2}{|c|}{ MDC } & \multicolumn{2}{|c|}{ MLC } & \multicolumn{2}{|c|}{ ANN } \\
\hline & OVA (\%) & Карра & OVA $(\%)$ & Kappa & OVA (\%) & Карра \\
\hline Spring & 72 & 0.43 & 73 & 0.44 & 72 & 0.40 \\
\hline Summer & 67 & 0.33 & 69 & 0.33 & 71 & 0.39 \\
\hline Autumn & 72 & 0.43 & 68 & 0.37 & 74 & 0.45 \\
\hline Winter & 81 & 0.61 & 82 & 0.63 & 83 & 0.64 \\
\hline
\end{tabular}

mean NDVI values and the thresholds between land-cover types. In general, the winter NDVI calculated from the three classes of bamboo in the area with conifers is relatively higher than the area without conifers. Winter NDVI was used to map bamboo coverage using a binary decision tree classifier. A high mapping accuracy for understory bamboo presence/absence was achieved with an overall accuracy of 89 percent $(\kappa=0.59)$. In addition, three density classes of bamboo was also successfully classified with an overall accuracy of 68 percent $(\kappa=0.48)$.

1983 ) is used to test for statistically significant differences in output images.

\section{Results}

\section{Determining the Optimal Season and Vegetation Index}

Table 3 results highlights that the highest correlations between vegetation index and bamboo cover were observed in leaf-off season (winter) with the $R^{2}$ value ranging from 0.47 to 0.65 . The weakest relationships were found in leaf-on or partly leafon seasons (spring, summer and autumn) with the $R^{2}$ value ranging from 0.01 to 0.13 . Winter NDVI appeared to give higher $R^{2}$ values than SAVI and EVI, which explained respectively 65 percent and 52 percent of variation in bamboo coverage for the areas without and with conifers. This relationship suggests that three classes of bamboo cover can be quantified adequately by using winter TM-derived NDVI (Table 3).

Producing the Highest Accuracy Map for the Presence/Absence of Conifer Table 4 details that the winter image yielded the highest map accuracy. The highest mapping accuracy was achieved by ANN with an overall mapping accuracy of 83 percent $(\kappa=0.64)$.

A kappa z-test for pairwise comparison in accuracy shows that there was significant difference between winter and other seasons, but no significant difference in accuracy as a result of the method used.

\section{Mapping Understory Bamboo Presence and Coverage Using NDVI}

Table 5 displays winter NDVI thresholds derived from the previous statistical analyses, that shows differences in

\section{Comparing the Mapping Accuracy with Multispectral Bands-based Approach}

The understory bamboo presence/absence was classified by using three multispectral bands-based classifiers (MDC, MLC, and ANN) in four seasons. The overall mapping accuracy and Kappa coefficient was compared to the results produced by winter NDVI thresholds-based DTC (Table 6), and the maps were shown in Figure 4a through $4 \mathrm{~d}$. The results show that the highest mapping accuracy was achieved with an overall mapping accuracy of 90 percent $(\kappa=0.63)$ by using the ANN classifier in winter, and then followed by DTC, MLC, and MDC. The lower overall mapping accuracies and extremely poor kappa coefficients were obtained in leaf-on and partly leaf-on seasons, regardless of the methods used. A kappa z-test for pairwise comparisons proved the leaf-off season (winter) was significantly different to the partly leaf-on and leaf-on seasons (spring, summer, and autumn) (Table 7). We therefore concluded that there was a significant difference on understory bamboo presence/absence mapping accuracy between the leaf-off and leaf-on as well as partly leaf-on seasons.

The three classes of bamboo coverage were also classified by three methods (MDC, MLC, and ANN) for the winter image. Note that only winter image was employed because the leafon images failed to discriminate the bamboo presence/absence according to previous results. The overall accuracies, kappa coefficients, and kappa variances from all three multispectralbased methods were compared to NDVI thresholds-based DTC approach (Table 8). The highest mapping accuracy was again achieved with an overall accuracy of 71 percent $(\kappa=0.54)$ by using ANN classifier, and then followed by MDC, MLC, and DTC classifiers, and the maps are shown in Figure $4 \mathrm{e}$ through $4 \mathrm{~h}$.

Table 3. $R^{2}$-Values for the Relationship Between the Three Vegetation indices and Three Classes of Bamboo Coverage in Four Seasons in Areas With and Without Conifers; note that the Values Followed BY $(*)$ ARE SignificANT at 0.01 CONFIDENCE LEVEL

\begin{tabular}{|c|c|c|c|c|c|c|c|c|}
\hline \multirow[t]{2}{*}{ v1 } & \multicolumn{4}{|c|}{ Bamboo in the area without conifer } & \multicolumn{4}{|c|}{ Bamboo in the area with conifer } \\
\hline & Spring & Summer & Autumn & Winter & Spring & Summer & Autumn & Winter \\
\hline NDVI & $0.13^{\star}$ & $0.05^{*}$ & $0.13^{*}$ & $0.65^{\star}$ & 0.01 & 0.01 & $0.11^{*}$ & $0.52^{*}$ \\
\hline SAVI & $0.10^{*}$ & $0.06^{*}$ & $0.11^{\star}$ & $0.51^{*}$ & 0.03 & 0.04 & $0.11^{\star}$ & $0.47^{\star}$ \\
\hline EVI & 0.09 * & $0.06^{*}$ & $0.11^{\star}$ & $0.53^{\star}$ & 0.03 & 0.04 & $0.12^{\star}$ & $0.48^{*}$ \\
\hline
\end{tabular}


Table 5. Winter nDVI Thresholds for Three Classes of Bamboo Coverage in Areas With and Without Conifers; Note that the Mean NDVI Values aRe at 0.05 Confidence LeVel, and " $N$ " Represents the Number of Training Samples

\begin{tabular}{|c|c|c|c|c|c|c|c|c|}
\hline \multirow[t]{2}{*}{ Bamboo cover } & \multicolumn{4}{|c|}{ NDVI in the area without conifer } & \multicolumn{4}{|c|}{ NDVI in the area with conifer } \\
\hline & Mean & Std. error & Thresholds & $N$ & Mean & Std. error & Thresholds & $\mathrm{N}$ \\
\hline No-bamboo & 0.40 & 0.011 & $<0.45$ & 18 & 0.47 & 0.006 & $<0.51$ & 33 \\
\hline Low-bamboo & 0.50 & 0.006 & $0.45-0.54$ & 58 & 0.54 & 0.005 & $0.51-0.56$ & 56 \\
\hline High-bamboo & 0.57 & 0.005 & $>0.54$ & 88 & 0.59 & 0.005 & $>0.56$ & 68 \\
\hline
\end{tabular}

Table 6. Comparison of OVerall Mapping Accuracies and Kappa Coefficients for Bamboo Presence/Absence from Four Different Classifiers in Four Seasons; Note "NC" means "Not ClassiFied" Because There was No Significant Difference Found Between the MeAn of NDVI AND Understory Bamboo Presence/Absence in These Seasons

\begin{tabular}{|c|c|c|c|c|c|c|c|c|}
\hline \multirow[t]{2}{*}{ Seasons } & \multicolumn{2}{|c|}{ MDC } & \multicolumn{2}{|c|}{ MLC } & \multicolumn{2}{|c|}{ ANN } & \multicolumn{2}{|c|}{ NDVI-DTC } \\
\hline & OVA (\%) & Карра & OVA $(\%)$ & Kappa & OVA $(\%)$ & Kappa & OVA (\%) & Kappa \\
\hline Spring & 69 & 0.24 & 76 & 0.18 & 81 & 0.22 & NC & NC \\
\hline Summer & 62 & 0.14 & 74 & 0.22 & 78 & 0.18 & NC & NC \\
\hline Autumn & 62 & 0.12 & 63 & 0.13 & 84 & 0.14 & NC & $\mathrm{NC}$ \\
\hline Winter & 84 & 0.55 & 87 & 0.59 & 90 & 0.63 & 89 & 0.59 \\
\hline
\end{tabular}

However, the kappa z-test showed that there is no significant difference between the methods used.

\section{Discussion}

\section{Best Season}

In this study, it was demonstrated that winter is the best season for predicting an evergreen understory bamboo species $B$. fargesii in a deciduous-dominated mixed temperate forest, regardless of the classification methods used. There are several reasons which may explain why winter is the most appropriate season for mapping understory bamboo. The first is because the deciduous canopy trees are leafless and do not block the view of ground features, especially evergreen understory bamboos. The second is that the leaf-off and die-off of most co-occurring shrubs and grass in winter creates a more uniform ground cover, which may greatly minimize the possibility of mis-categorized pixels. However, Linderman et al. (2004) reported that the understory bamboo misclassification caused by co-occurring grass and shrubs using a leaf-on image is big problem that could not be solved by a neural network classifier. Thirdly, it was believed that the difference in spectral properties between understory bamboo and overstory forest, as well as reduced photosynthesis in evergreen coniferous forest in winter, contributed to the higher bamboo mapping accuracy obtained in mixed deciduous/ coniferous forests. As Fukui et al. (2004) reported that the spectral reflectance of wild bamboo forests is higher in nearinfrared than evergreen coniferous forests, but it is much lower than evergreen broadleaf and deciduous broadleaf forests. Moreover, our research complements an earlier study by Stenback and Congalton (1990), who emphasized that the acquisition date of the images is considered to be the critical factor controlling the level of understory classification obtainable. They therefore suggested that the analysis could be repeated using different acquisition dates selected on the basis of the dominant canopy and understory phenology.

\section{Optimal Vegetation Index}

It was found that NDVI has a relatively stronger relationship with understory bamboo coverage compared with SAVI and
EVI. Because bamboo cover is high in the study area, it is reasonable that SAVI performs poorly relative to NDVI, as SAVI is optimized for low vegetation cover (Huete, 1988). The EVI was designed to improve sensitivity to high biomass regions and reduce in atmospheric influences (Huete et al., 2002). However, this study showed that there is no saturation problem in winter, as the mean NDVI value (for the high bamboo cover) was 0.59 . Moreover, an atmospheric correction was conducted before the calculation of NDVI, further reducing the advantages of EVI compared with NDVI.

Bamboo Presence and Cover Mapping by Using Four Classification Methods This study tested the effectiveness of a winter NDVI thresholds-based decision tree approach for classifying understory bamboo coverage. The results were considered good with an overall accuracy of 89 percent $(\kappa=0.59)$ for bamboo presence/absence, and satisfactory with an overall accuracy of 68 percent $(\kappa=0.48)$ for three classes of bamboo coverage. To our knowledge, this study is the first attempt at mapping understory bamboo cover as three classes (instead of presence/absence). As noted above, retrieval of bamboo coverage is important for understanding wildlife distribution patterns and population dynamics based on habitat requirement.

Three traditional multispectral bands-based classifiers (MDC, MLC, and ANN) mapped bamboo coverage, and were compared with NDVI thresholds-based DTC. The kappa ztest showed that there is no significant difference between the methods used. With respect to mapping the three density classes of bamboo, ANN produced the highest accuracy, although it is not significantly higher than NDVI thresholds-based DTC possibly because the additional spectral information provided by TM band 5 was utilized by the ANN (Stenback and Congalton, 1990).

Differences in classification accuracy have been attributed to many factors (Richards and Jia, 1999), including how the training data are modeled by the assumption of the parametric or nonparametric classifier (Strahler, 1980; Skidmore et al., 1997), the number of training pixels (Foody 


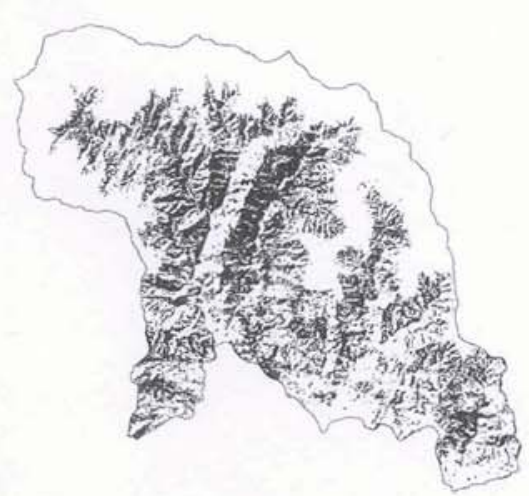

(a)

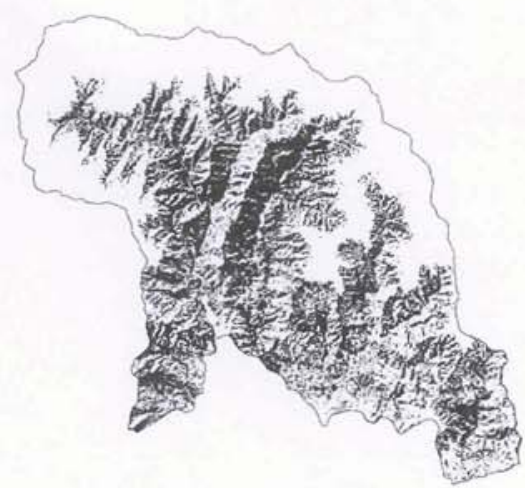

(b)

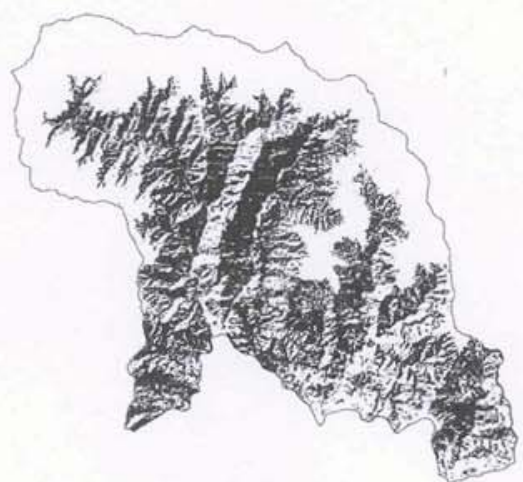

(c)

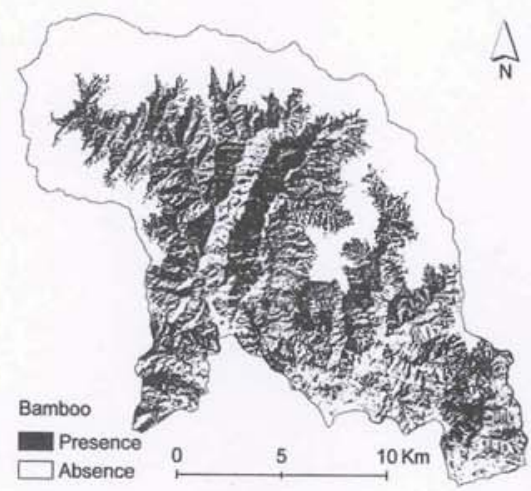

(d)

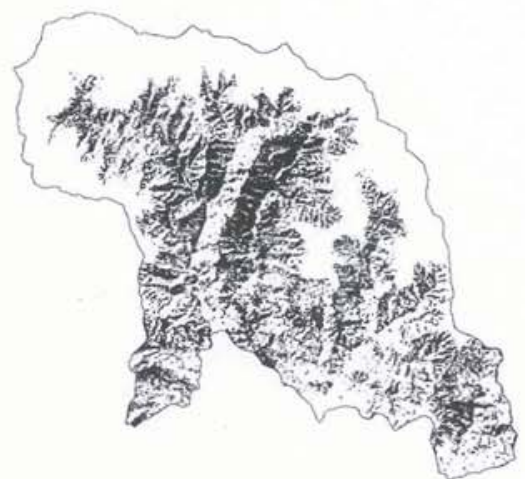

(e)

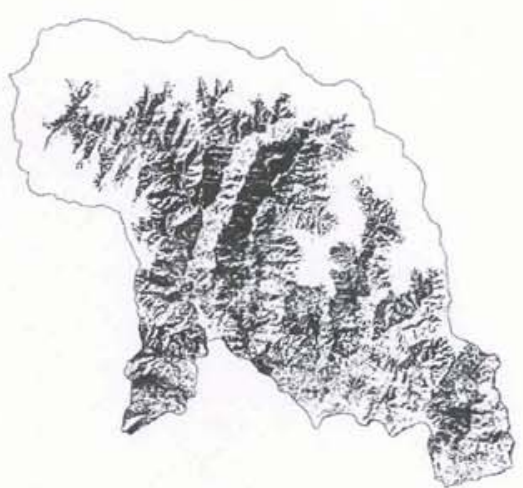

(f)

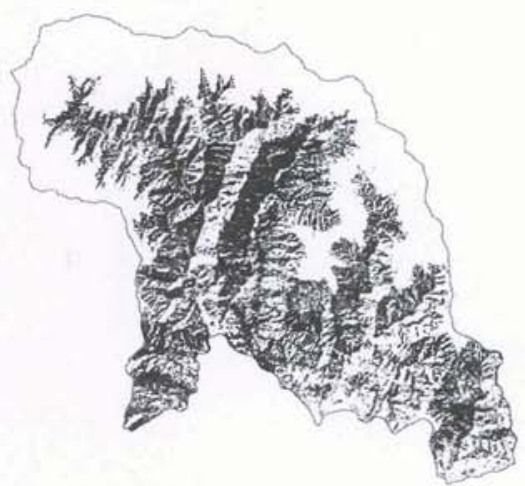

(g)

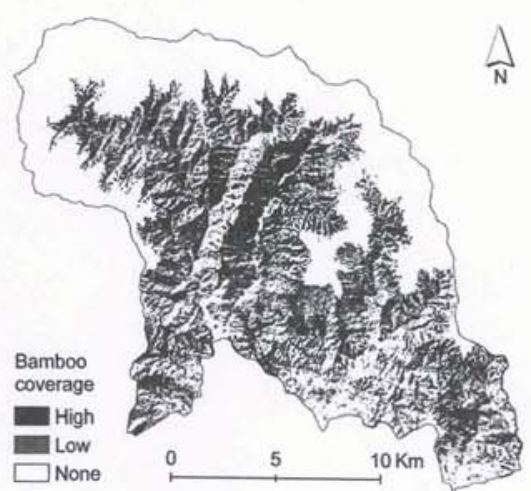

(h)

Figure 4. The presence/absence maps of evergreen understory bamboo (B. Fargesii) (a, b, c, and d), as well as the maps of three classes of bamboo coverage $(e, f, g$, and $h$ ) in Foping Nature Reserve produced by four different methods using winter image. Among the maps, (a) and (e) are derived from MDC; the maps (b) and ( $f$ ) are derived from MLC; the maps (c) and ( $g$ ) are produced by ANN; the maps (d) and (h) are produced by winter NDVI-DTC, respectively. 
Table 7. Kappa Z-test for Pairwise Comparison Between any Two of Four SeAsons (SPRING, SUMmer, AUTUMN, AND WINTER) FOR BAMBOO Presence/Absence from Three Classifiers (MDC, MLC, and ANN); Note the Values Followed by $(*)$ are Significant at Higher than 1.96 at $\alpha=$ 0.05

\begin{tabular}{|c|c|c|c|c|c|}
\hline Classifiers & Season & Spring & Summer & Autumn & Winter \\
\hline \multirow[t]{4}{*}{ MDC } & Spring & - & & & \\
\hline & Summer & $2.88^{*}$ & - & & \\
\hline & Autumn & $3.46^{\star}$ & 0.59 & - & \\
\hline & Winter & $10.45^{\star}$ & $13.53^{\star}$ & $14.16^{\star}$ & - \\
\hline \multirow[t]{4}{*}{ MLC } & Spring & - & & & \\
\hline & Summer & 1.26 & - & & \\
\hline & Autumn & 1.32 & $2.54^{\star}$ & - & \\
\hline & Winter & $14.55^{\star}$ & $13.00^{\star}$ & $15.55^{\star}$ & - \\
\hline \multirow[t]{4}{*}{ ANN } & Spring & - & & & \\
\hline & Summer & 1.12 & - & & \\
\hline & Autumn & 0.58 & 0.58 & - & \\
\hline & Winter & $15.44^{\star}$ & $16.22^{\star}$ & $16.58^{\star}$ & - \\
\hline
\end{tabular}

Table 8. Overall Mapping Accuracies, Kappa Coefficients and Kappa VARIANCES for THREe Classes of BAMBOO COVERAge from FOUR DifFERENT Classifiers in Leaf-off Season (Winter). Note that None of the ClassiFIERS HAVE A SIGNIFICANT DIFFERENCE IN ACCURACY (KaPPA Z TEST PARE-WISE COMPARISON, $Z<1.96$ AT $\alpha=0.05$ )

\begin{tabular}{lccc}
\hline Classifiers & OVA (\%) & Kappa & Kappa variance \\
\hline $\begin{array}{l}\text { Mahalanobis distance } \\
\text { classifier (MDC) }\end{array}$ & 69 & 0.51 & 0.00065 \\
$\begin{array}{l}\text { Maximum likelihood } \\
\text { classifier (MLC) }\end{array}$ & 68 & 0.49 & 0.00066 \\
$\begin{array}{l}\text { Artificial neural } \\
\text { networks (ANN) }\end{array}$ & 71 & 0.54 & 0.00062 \\
$\begin{array}{l}\text { NDVI-based decision } \\
\text { tree classifier (NDVI-DTC) }\end{array}$ & 68 & 0.48 & 0.00067 \\
\hline
\end{tabular}

et al., 2006), the landscape structure and homogeneity of training areas (Hubert-Moy et al., 2002), selection of a classification scheme (Prenzlel and Treitz, 2005 ), the type and quality of the imagery (Underwood et al., 2007), and the quality of the ground truth data (Congalton and Green, 1999). It has been shown (Richards and Jia, 1999) that many of these factors are empirical and vary from case to case, and therefore rely on an analyst's skills in both operating a image processing systems, but also in the "art" of understanding a classification. In this study, a large dataset was available, the images were carefully corrected for both geometric and radiometric properties, the ground truth data was of high quality, and the training areas were rather homogeneous because of the use of a winter (leaf-off) image. Consequently, these factors resulted in very high accuracy results (especially for a mountainous forested study area) with no statistical difference in the performance of the classifiers.

The problem of estimating bamboo cover in the field is difficult due to poor access, steep terrain, and dense understory. As detailed in the methods, we chose a visual estimation approach. Using instruments to measure incident radiation below and above the forest canopy (and hence infer LAI) may be strictly more objective, but the reality of the forest conditions makes the practical use of these instruments impossible.

\section{Conclusions}

In this paper, the difference in phenological stages between overstory and understory, and its impact on evergreen understory bamboo mapping was investigated. We conclude that: (a) winter imagery significantly improves understory bamboo cover mapping accuracy regardless of the classification methods used, and (b) winter vegetation indices, especially winter NDVI, can be successfully used to map evergreen understory bamboo coverage. The simplicity, robustness and availability of NDVI have the potential to quickly identify the "hot spots" of understory bamboo over a large region.

The presence and abundance of understory bamboo is a key factor in giant pandas habitat assessment, but it has normally been assumed to have a constant cover over space and time. The direct result of this research is an improved understanding of the distribution pattern of understory bamboo abundance at Foping Nature Reserve and other forests in central China. On the basis of these results, a more accurate assessment and modeling for suitable giant panda habitat can be achieved.

\section{Acknowledgments}

This research was funded by the International Institute for Geo-information Science and Earth Observation (ITC), the Netherlands. We are grateful for the support of the World Wide Fund for Nature (WWF Netherlands) and the Institute of Zoology of the Chinese Academy of Sciences. We appreciate the constructive comments from the two anonymous reviewers.

\section{References}

Ardö, J., and P. Pilesjö, 1992. On the accuracy of the global positioning system - A test using a hand-held receiver, International Journal of Remote Sensing, 13(16):3229-3233.

Borkowski, J., and K. Furubayashi, 1998. Seasonal changes in number and habitat use of foraging sika deer at the high altitude of Tanzawa Mountains, Japan, Acta Theriologica, 43(1):95-106.

Cohen, J., 1960. A coefficient of agreement for nominal scales, Educational and Psychological Measurement, 20(1):37-46.

Colby, J.D., 1991. Topographic normalization in rugged terrain, Photogrammetric Engineering \& Remote Sensing, 57(5):531-537.

Congalton, R.G., R.G. Oderwald, and R.A. Mead, 1983. Assessing Landsat classification accuracy using discrete multivariate analysis statistical techniques, Photogrammetric Engineering \& Remote Sensing, 49(12):1661-1668.

Congalton, R.G., and K. Green, 1996. Assessing the Accuracy of Remotely Sensed Data: Principles \& Practices, Lewis Publishers, London, $137 \mathrm{p}$.

Diaz, I.A., J.J. Armesto, S. Reid, K.E. Sieving, and M.F. Willson, 2005. Linking forest structure and composition: Avian diversity in successional forests of Chiloe' Island, Chile, Biological Conservation, 123(1):91-101.

Dymond, J.R., P.R. Stephens, P.F. Newsome, and R.H. Wilde, 1992 Percent vegetation cover of a degrading rangeland from SPOT, International Journal of Remote Sensing, 13:1999-2007.

Flores, F.J., 2003. Using Hyperspectral Remote Sensing to Estimate Leaf Area Index of Loblolly Pine Plantations, Ph.D. dissertation, North Carolina State University, Raleigh, North Carolina, 115 p.

Foody, G.M., A. Mathur, C. Sanchez-Hernandez, and D.S. Boyd, 2006. Training set size requirements for the classification of a specific class, Remote Sensing of Environment, 104 (1):1-14.

Franklin, J.F., T. Maeda, Y. Ohsumi, H. Yagi, and M. Hawk, 1979. Subalpine coniferous forests of central Honshu, Japan, Ecological Monographs, 49(3):311-334.

Fukui, Y., T. Tachikawa, and Y. Imai, 2004. Mapping bamboo forest expansion in the suburb of Fukuoka city using Aster data, AARS Web Proceedings, URL: http://www.aars-acrs.org/acrs/ proceedings2004.php, Asian Association on Remote sensing (last date accessed: 01 October 2008). 
Gong, H., Z. Zeng, X. Gao, Q. Liang, and Y. Song, 2006. Species of birds and mammals feeding on bamboo in Foping National Nature Reserve, Chinese Journal of Zoology, 41(3):31-36 (in Chinese)

Goodenough, D.G., A.S. Bhogall, H. Chen, and A. Dyk, 2001. Comparison of methods for estimation of Kyoto Protocol products of forests from multitemporal Landsat, Proceedings of IEEE 2001 International Geoscience and Remote Sensing Symposium, IGARSS'01, July, Sydney, Australia, pp. 764-767.

Greenberg, J.A., S.Z. Dobrowski, and S.L. Ustin, 2005. Shadow allometry: Estimating tree structural parameters using hyperspatial image analysis, Remote Sensing of Environment, 97(1):15-25.

Hansen, M., R. Dubayah, and R. DeFries, 1996. Classification trees: An alternative to traditional land cover classifiers, International Journal of Remote Sensing, 17:1075-1081.

Hubert-Moy, L., A. Cotonnec, L. Le Du, A. Chardin, and P. Perez, 2001. A comparison of parametric classification procedures of remotely sensed data applied on different landscape units, Remote Sensing of Environment, 75(2):174-187.

Huete, A.R., 1988. A soil adjusted vegetation index (SAVI), Remote Sensing of Environment, 25(3):295-309.

Huete, A.R., K. Didan, T. Miura, E.P. Rodriguez, X. Gao, and L.G. Ferreira, 2002. Overview of the radiometric and biophysical performance of the MODIS vegetation indices, Remote Sensing of Environment, 83(1-2):195-213.

Joshi, C., J. De Leeuw, J. Van Andel, A.K. Skidmore, D. Lekhak-Hari, I. Van Duren, and N. Norbu, 2006. Indirect remote sensing of a cryptic forest understory invasive species, Forest Ecology and Management, 225(1-3):245-256.

Kaufman, Y.J., and D. Tanré, 1992. Atmospherically resistant vegetation index (ARVI) for EOS-MODIS, IEEE Transactions on Geoscience and Remote Sensing, 30:261-270.

Kent, M., and P. Coker, 1992. Vegetation Description and AnalysisA Practical Approach, John Wiley, New York, 363 p.

Linderman, M., J. Liu, J. Qi, L. An, Z. Ouyang, J. Yang, and Y. Tan, 2004. Using artificial neural networks to map the spatial distribution of understory bamboo from remote sensing data, International Journal of Remote Sensing, 25(9):1685-1700.

Liu, H., and A. Huete, 1995. A feedback based modification of the NDVI to minimize canopy background and atmospheric noise, IEEE Transactions on Geoscience and Remote Sensing, 33(2):457-465.

Liu, J., M. Linderman, Z. Ouyang, L. An, J. Yang, and H. Zhang, 2001. Ecological degradation in protected areas: The case of Wolong Nature Reserve for giant pandas, Science, 292:98-101.

Liu, X., A.K. Skidmore, T. Wang, Y. Yong, and H.H.T. Prins, 2002. Giant panda movements in Foping Nature Reserve, China, Journal of Wildlife Management, 66(4):1179-1188.

Liu, X., A.G. Toxopeus, A.K. Skidmore, X. Shao, G. Dang, T. Wang, and H.H.T. Prins, 2005. Giant panda habitat selection in Foping Nature Reserve, China, Journal of Wildlife Management, 69(4):1623-1632.

Loucks, C.J., Z. Lu, D. Eric, D. Wang, D. Fu, and H. Wang, 2003. The giant pandas of the Qinling Mountains, China: A case study in designing conservation landscapes for elevational migrants, Conservation Biology, 17(2):558-565.

McKenzie, D., and C.B. Halpern, 1999. Modeling the distributions of shrub species in Pacific northwest forests, Forest Ecology and Management, 114(2-3):293-307.

Morain, S.A., 1986. Surveying China's agricultural resources: Patterns and progress from space, Geocarto International, 1:15-24.

Myneni, R.B., F.G. Hall, P.J. Sellers, and A.L. Marshak, 1995. The interpretation of spectral vegetation indexes, IEEE Transactions on Geoscience and Remote Sensing, 33(2):48-486.

Myneni, R.B.Y. Knyazikhin, J.L. Privette, and J. Glassy, 2002. Global products of vegetation leaf area and fraction absorbed PAR from year one of MODIS data, Remote Sensing of Environment, $83(1-2): 214-231$.

Pal, M., and P.M. Mather, 2003. An assessment of the effectiveness of decision tree methods for land cover classification, Remote Sensing of Environment, 86(4):554-565.
Pan, W., Z. Gao, and Z. Lu, 1988. The Giant Panda's Natural Refuge in the Qinling Mountains, Beijing University Press, Beijing, 245 p. (in Chinese).

Prenzlel, B., and P. Treitz, 2005. Comparison of function- and structure-based schemes for classification of remotely sensed data, International Journal of Remote Sensing, 26(3):543-561.

Purevdorj, T., R. Tateishi, T. Ishiyama, and Y. Honda, 1998. Relationships between percent vegetation cover and vegetation indices, International Journal of Remote Sensing, 19(18):3519-3535.

Reid, D.G., J. Hu, S. Dong, W. Wang, and Y. Huang, 1989. Giant panda Ailuropoda melanoleuca behaviour and carrying capacity following a bamboo die-off, Biological Conservation, 49(2):85-104.

Reid, D.G., J. Hu, and Y. Huang, 1991. Ecology of the red panda Ailurus fulgens in the Wolong Reserve, China, Journal of Zoology, 225:347-364.

Reid, S., I.A. Diaz, J.J. Armesto, and M.F. Willson, 2004. Importance of native bamboo for understory birds in Chilean temperate forests, The Auk, 121(2):515-525.

Ren, Y., M. Wang, M. Yue, and Z. Li, 1998. Plants of Giant Panda's Habitat of Qinling Mountains, Shaanxi Science and Technology Press, Xian, China, 488 p. (in Chinese).

Rettie, W.J., J.W. Sheard, and F. Messier, 1997. Identification and description of forested vegetation communities available to woodland caribou: Relating wildlife habitat to forest cover data, Forest Ecology and Management, 93(3):245-260.

Richards, J.A., and X. Jia, 1999. Remote Sensing Digital Analysis: An Introduction, Third edition, Springer-Verlag, Berlin, $363 \mathrm{p}$.

Richter, R., 1996. A spatially adaptive fast atmospheric correction algorithm, International Journal of Remote Sensing, $17(6): 1201-1214$.

Richter, R., 1998. Correction of satellite imagery over mountainous terrain, Applied Optics, 37(18):4004-4015.

Rouse, J.W., R.H. Hass, J.A. Schell, and D.W. Deering, 1973. Monitoring vegetation systems in the Great Plains with ERTS, Proceedings of the Third ERTS Symposium (S.S. Freden, E.P. Mercanti, and M.A. Becker, editors), U.S. Government Printing Office, Washington, D.C., pp. 309-317.

Schaller, G.B., J. Hu, W. Pan, and J. Zhu, 1985. The Giant Pandas of Wolong, The University of Chicago Press, Chicago and London, $318 \mathrm{p}$.

Simard, M., S.S. Saatchi, and G.D. Grandi, 2000. The use of decision tree and multiscale texture for classification of JERS-1 SAR data over tropical forest, IEEE Transactions on Geoscience and Remote Sensing, 38(5):2310-2321.

Skidmore, A.K., B.J. Turner, W. Brinkhof, and E. Knowle, 1997. Performance of a neural network: Mapping forests using GIS and remotely sensed data, Photogrammetric Engineering \& Remote Sensing, 63(5):501-514.

State Forestry Administration, 2006. The Third National Survey Report on Giant Pandas in China, Science Press, Beijing, 355 p. (in Chinese).

Stefanov, W.L., M.S. Ramsey, and P.R. Christenson, 2001. Monitoring urban land cover change: An expert approach to land cover classification of semiarid to arid urban centers, Remote Sensing of Environment, 77(2):173-185.

Stenback, J.M., and R.G. Congalton, 1990. Using thematic mapper imagery to examine forest understory, Photogrammetric Engineering \& Remote Sensing, 56(9):1285-1290.

Strahler, A.H., 1980. The use of prior probabilities in maximum likelihood classification of remotely sensed data, Remote Sensing of Environment, 10:135-163.

Taylor, A.H., and Z. Qin, 1988. Regeneration patterns in old-growth Abies-Betula forests in the Wolong Natural Reserve, Sichuan, China, Journal of Ecology, 76(4):1204-1218.

Taylor, A.H., and Z. Qin, 1987. Culm dynamics and dry matter production of bamboo in the Wolong and Tangjiahe giant panda reserves, Sichuan, China, Journal of Applied Ecology, $24: 419-433$.

Tian, X., and Q. Liu, 1985. Distribution of Bashania fargesii on the south slope of the Qinling Mountains, Bamboo Research, 1:13-17 (in Chinese). 
Townsend, P.A., and S.J. Walsh, 2001. Remote sensing of forested wetlands: Application of multitemporal and multispectral satellite imagery to determine plant community composition and structure in southeastern USA, Plant Ecology, 157(2):129-149.

Townshend, J., C. Justice, W. Li, C. Gurney, and J. McManus, 1991. Global land cover classification by remote sensing: present capabilities and future possibilities, Remote Sensing of Environment, 35:243-257.

Tucker, C.J., J.R.G. Townshend, and T.E. Goff, 1985. African landcover classification using satellite data, Science, 227(4685):369-375.

Turner, D.P., W.B. Cohen, R.E. Kennedy, K.S. Fassnacht, and J.M. Briggs, 1999. Relationships between leaf area index and Landsat TM spectral vegetation indices across three temperate zone sites, Remote Sensing of Environment, 70(1):52-68.

Underwood, E.C., S.L. Ustin, and C.M. Ramirez, 2007. A comparison of spatial and spectral image resolution for mapping invasive plants in coastal California, Environmental Management, 39(1):63-83.
Veblen, T.T., 1982. Growth patterns of chusquea bamboos in the understory of Chilean Nothofagus forests and their influences in forest dynamics, Bulletin of the Torrey Botanical Club, 109(4):474-487.

Warner, M., 2002. Assessing habitat utilization by neotropical primates: A new approach, Primates, 43(1):59-71.

Wittich, K.P., and O. Hansing, 1995. Area-averaged vegetative cover fraction estimated from satellite data, International Journal of Biometereology, 38(4):209-215.

Xu, M., P. Watanachaturaporn, P.K. Varshney, and M.K. Arora, 2005. Decision tree regression for soft classification of remote sensing data, Remote Sensing of Environment, 97(3):322-336.

Yue, M., G. Dang, and L. Yong, 1999. The basic features of vegetation of Foping Nature Reserve in Shaanxi province, Journal of Wuhan Botanical Research, 17(1):22-28 (in Chinese).

(Received 14 June 2007; accepted 01 October 2007; revised 30 October 2007)

\section{ASPRS Code of Ethics}

Honesty, justice, and courtesy form a moral philosophy which, associated with mutual interest among people, should be the principles on which ethics are founded.

Each person who is engaged in the use, development, and improvement of the mapping sciences (Photogrammetry, Remote Sensing, Geographic Information Systems, and related disciplines) should accept those principles as a set of dynamic guides for conduct and a way of life rather than merely for passive observance. It is an inherent obligation to apply oneself to one's profession with all diligence and in so doing to be guided by this Code of Ethics.

Accordingly, each person in the mapping sciences profession shall have full regard for achieving excellence in the practice of the profession and the essentiality of maintaining the highest standards of ethical conduct in responsibilities and work for an employer, all clients, colleagues and associates, and society at large, and shall...

1. Be guided in all professional activities by the highest standards and be a faithful trustee or agent in all matters for each client or employer.

2. At all times function in such a manner as will bring credit and dignity to the mapping sciences profession.

3. Not compete unfairly with anyone who is engaged in the mapping sciences profession by:

a. Advertising in a self-laudatory manner;

b. Monetarily exploiting one's own or another's employment position;

c. Publicly criticizing other persons working in or having an interest in the mapping sciences;

d. Exercising undue influence or pressure, or soliciting favors through offering monetary inducements.

4. Work to strengthen the profession of mapping sciences by:

a. Personal effort directed toward improving personal skills and knowledge; b. Interchange of information and experience with other persons interested in and using a mapping science, with other professions, and with students and the public;

c. Seeking to provide opportunities for professional development and advancement of persons working under his or her supervision;

d. Promoting the principle of appropriate compensation for work done by person in their employ.

5. Undertake only such assignments in the use of mapping sciences for which one is qualified by education, training, and experience, and employ or advise the employment of experts and specialists when and whenever clients' or employers' interests will be best served thereby.

6. Give appropriate credit to other persons and/or firms for their professional contributions.

7. Recognize the proprietary, privacy, legal, and ethical interests and rights of others. This not only refers to the adoption of these principles in the general conduct of business and professional activities, but also as they relate specifically to the appropriate and honest application of photogramme try, remote sensing, geographic information systems, and related spatial technologies. Subscribers to this code shall not condone, promote, advocate, or tolerate any organization's or individual's use of these technologies in a manner that knowingly contributes to:

a. deception through data alteration;

b. circumvention of the law;

c. transgression of reasonable and legitimate expectation of privacy. 